\title{
Large Crankshaft Connecting Rod Journal Fillet Multi-axis Linkage Machining Method Research and Finite Element Analysis
}

\author{
Fei FU ${ }^{1}$, Xiao-Yan BAO² \\ 1. Shanghai University of Engineering Science, Shanghai, 200437.
}

2. Starrett tools (SuZhou) LTD, Shanghai, 200432.

Keywords: Crankshaft, Multi axis linkage, Processing method, Finite element analysis.

\begin{abstract}
The crankshaft is the important parts, engine crankshaft in multi-axis linkage machining crankshaft connecting rod journal fillet, due to the current solution is expensive, time consuming is too long, this paper proposes an improved scheme, make better able to take advantage of the present condition of finish machining, reduce the usage of cutting tool. To reduce the cost.
\end{abstract}

\section{Introduction}

Crankshaft engine is important component, its role is to each cylinder piston work passed into the flywheel and camshaft, output power outward. Due to the complexity of the crankshaft shape, poor rigidity, and along the length direction and the rigid circular parties up are not equal, so this will lead to the main journal circle weeks parties up to produce the elastic deformation of different sizes, have great influence to the shape of the workpiece precision. The merits of the processing quality for the life of the engine and the working reliability has an important influence. Study how to control and reduce the crankshaft in the machining process caused by elastic deformation error and to improve the quality of the crankshaft, prolong service life has important practical significance.

In this paper, the crankshaft with a engine as an example, the use of Multi-axis linkage machining technology, puts forward a new method of large crankshaft connecting rod journal fillet processing. Traditional two process crankshaft grinding points respectively in two different grinding machine grinding was carried out on the main journal river connecting rod journal, requires two positioning, thus there exists large positioning error, low machining efficiency of defect, through the tangent point tracing grinding technology and the development of numerical control technology and appear a kind of new process of centralized grinding method. Current based on tree-axis linkage of crankshaft connecting rod journal tangent point tracking grinding method, the grinding wheel can be in the $\mathrm{X}$ axis and $\mathrm{Y}$ axis interpolation of two direction and in the research of this paper is in addition to the $\mathrm{X}, \mathrm{Y}, \mathrm{Z}$ three straight axis is equipped with rotation axis of two rotary heads, through the combination of roughing and fine machining technology, can increase the machining precision.

Within the traditional processing is often use turning, milling, grinding and other processing methods to achieve. At the time of turning the crankshaft, because the main journal and the center of the connecting rod journal axis not in a line, usally need to use clamp to set the crankshaft at the right place, cause the increase of the clamping error. Generally there is a widespread process of dispersion, a great error in the process, equipment, covers big area, efficiency under the shortcomings. Along with the continuous application of turning milling compound machining center, One time clamping, can achieve all of the crankshaft processing object is rough machining, semi-finishing, if under the condition of high configuration can even finish machining process.

\section{Introduction of the Composite Processing Technology of Lathe and Milling Machine}

Turning- milling composite processing technology is the core of on one device, a clamping automatically on complex shape, Multi working procedure and high machining accuracy requirements of special shaped revolving body, turning, milling, drilling, boring and tapping process of new technology with five-axis linkage. And turning- milling machining center also has the function, can will be the main journal lathe, connecting rod journal lathe, CNC boring and milling machine, radial drilling machine and oblique hole drilling machine and other equipment 
more than feature set on a turning milling machining center, one-time clamping automatically Machining main journal, free end and output end, connecting rod journal, balance iron surface installation, the crank arm external circular contour and inclined plane turning, milling, about 16 working days; Complete balance iron installed side hole, oblique oil hole and main journal oil hole neck and connecting rod of the oil hole drilling process, takes about 3 working days; Finally the grinding process, complete the main journal, connecting rod neck processing, grinding process to fulfill the requirements of main journal, the precision of the connecting rod journal.

Large crankshaft crank arm shape generally consists of multistage eccentric circular arc and straight line, the traditional processing method is generally by making eccentric fixture Will finish the crankshaft clamping on the horizontal lathe turning into, also have use whirlwind turning tuned eccentricity machining, no matter use what method, when the crank arm is processed with different phase angles, the crank shaft is turned, so the machining efficiency is very low. Now, with the continuous application of complex numerical control machine tool, crank arm shape now are generally in one-time clamping processing and milling center last completed.

At present, most of the crankshaft manufacturers in the turning-milling center on the processing of the arm of the crankshaft use of the turning-milling center of the macro program software package programming, with most domestic application of shenyang machine tool manufacturers HTM1251000 crankshaft milling center as an example,programming to enter the curve of each section of the arm shape and a straight line of the starting point, the end point of the coordinates (or arc angle) and the radius then the package automatically generate the program, the program will be segmented processing each arc and straight line, this kind of machining method for each processing period of circular arc, the crankshaft to return to the origin, the cutting tool must be re - cutting, cutting, cutting back, cause feeding time is far greater than cutting time, greatly affects the processing efficiency. In addition, the processing will produce large gear mark is in two arcs, sometimes even causing undercutting.

\section{The Working Principle of Turning- Milling Composite Processing}

The process of turning milling, according to the relative position of cutter and workpiece can be divided into peripheral milling and face milling; According to the milling cutter and workpiece rotation direction can be divided into climb milling and up milling.

Turnig-milling processing based on rotation axis of workpiece and cutting tool rotation axis relative position is different, and Turnig-milling process can be divided into axial turning milling and orthogonal turning milling and general turning milling. The axial turning milling with orthogonal turning milling respectively have their own characteristics and limitations.
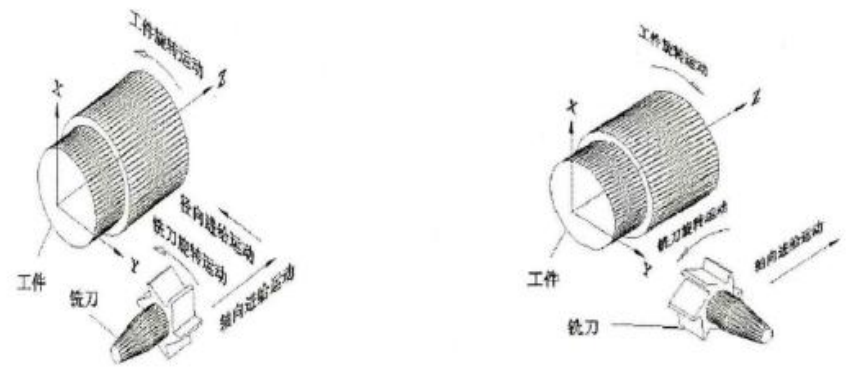

Fig.1 Two types of turning milling processing

\section{The Solution of the Problem in the Application of Turning-milling Technology}

In the process of crankshaft milling roughing and semi-finishing, the biggest difficulty is the crank arm and the connecting rod journal fillet processing, processing capacity accounted for $75 \%$ of the total rough machining. In the process of crankshaft machining, processing for the first time using four blade wafer vertical milling cutter eccentricity follow-up processing way. Due to the crank 
eccentric diameter $(45 \mathrm{~mm})$, large triaxial linkage maximum speed just can reach $55 \mathrm{r} / \mathrm{min}$, and machining allowance is very big, especially connecting rod journal root, $15 \sim 20 \mathrm{~mm}$, the largest margin in actual processing, processing of vibration is larger, the blade wear, machining efficiency is low, there needs to be optimized process. The follow-up milling force analysis shows that using milling, each point on the cutting edge Angle is changed, mainly for the radial forces during processing, due to the crankshaft of slender structure, poor rigidity, wafer cutter cutting force itself, especially the multi edge cutting, produce great vibration in machining process. By the same token, the milling of crank, mainly for the milling, the cutting thickness of each point of the circular arc blade is changed, asymmetrical, chip from zero to thick, produce instability, chock appeared on the knife, the blade wear quickly. As shown in figure 2, domestic tool, there is no better solution, then using the United States kennametal provides processing scheme, the scheme design of double circular arc lathe tool as shown in figure 3, and write four axis linkage machining program, optimization of connecting rod journal and side milling for follow-up turning processing way, So as to improve the stress of the workpiece during the machining process. After debugging and actual processing verification, solves the processing vibration and blade wear. However, the previous tool cost is very high., production cycle for up to six months, the late tool consumption is very big also, each axis machining tool to replace all, high cost, makes the production cost.

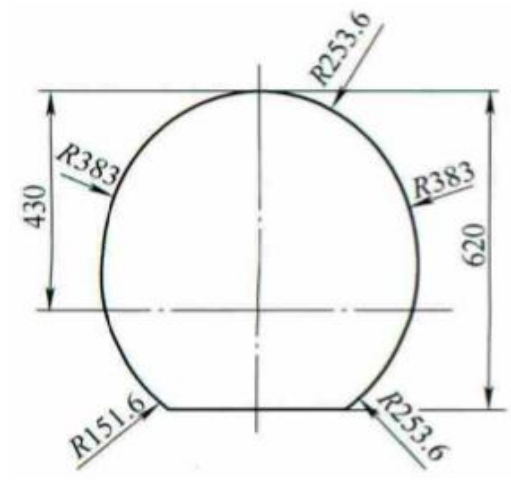

Fig.2 five period of circular arc of the crankshaft crank arm shape

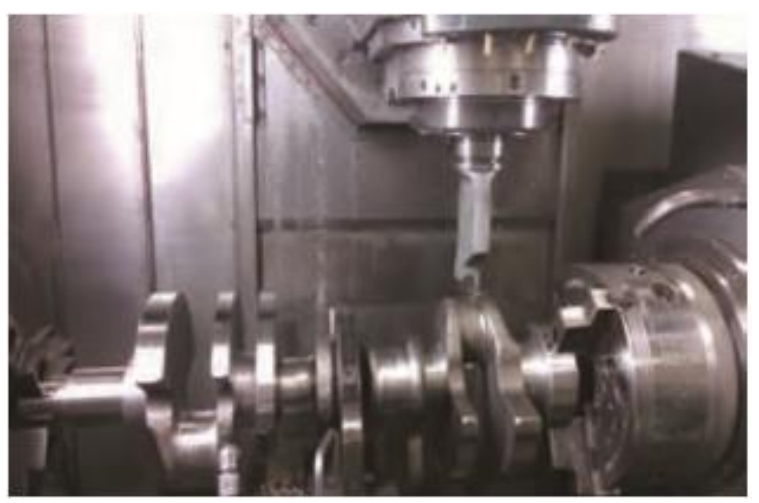

Fig.3 turning milling figure

\section{A Multi-tool Milling Crankshaft Main Journal and Its Manufacturing Techniques}

Through the analysis and calculation of the crankshaft of the engine, It can use the standard spherical milling cutter multi -axis linkage machining method to implement the fillet processing, processing of crankshaft, the cutting tool with the connecting rod neck rotation while processing, each processing cycle, cutting tool along the axial moving to the next place, continue to follow-up processing, until the whole round curved surface machining. This scheme does not need special milling cutter, tool cost is greatly reduced, at the same time because of the cutter contact area is small, significantly lower cutting force, cutting tool rotation speed and feed rate can be greatly improved, also have to improve processing efficiency. To achieve this kind of machining method, 
need of CNC system for coordinating, excellent turning milling machining procedure for milling processing of high quality, high yield, low consumption, riding a important role. Need good CNC system to cooperate, excellent turn milling program play an important role for the realization of high quality, high yield and low consumption.

Program design is a crucial link, the nc machining is the movement of the machine tool machining sequence and relative displacement of the workpiece and cutting parameters are expressed in the form of procedures section process. Now the UG software as an example the process description as below.

(1) Establish the 3D model of the connecting rod neck.

(2) make a reasonable programming process and tool path. Into the software processing module, choose four-axis surface processing programming, processing into semi-finishing and finish machining, Cutting tool combined with existing conditions, semi-finishing with mitsubishi $30 \mathrm{~mm}$ inserted ball-nose end mill, each cutter spacing of $5 \mathrm{~mm}$, margin of $0.5 \mathrm{~mm}$, set the programming tool tilted 12 degrees, start click on the top of the crank arm under the knife, to avoid blade damage, feeding path adopted the circumferential direction, the whole round curved surface processing 7 times, finishing with $20 \mathrm{~mm}$ spherical milling cutter, each cutter spacing $2 \mathrm{~mm}$, polishing allowance of $0.03 \mathrm{~mm}$.

(3) UG generated process track just cutter location files, need to be combined with the equipment of numerical control system can generate NC program using post-processing, UG software using POST post-processing procedure, however, its own post-processing program can not directly suitable for turning-milling center HTM1251000, therefore requires special customization. According to the equipment structure, Selected the B and C double axis five-axis linkage structure, Need to pay attention to is that the $\mathrm{B}$ axis to enter the radius of rotation, $\mathrm{C}$ axis of rotation must be consistent with the machine. In addition, due to the shenyang machine tool plant and milling center does not support G93, thus post-processing G94 speed control is adopted, however, due to the generated program is basically every $2.5^{\circ}$ a point, so the actual $\mathrm{C}$ axis rotation speed was more uniform.

(4) After generating the NC program, in order to be prudent, must be on the computer to simulate the NC program after processing, in order to check whether the crankshaft machining center in the center of the process of cutting, interference and other issues. Vericut software was used to verify the NC machining simulation system developed by American CGTECH company.This software can simulate the $\mathrm{NC}$ machining process of $\mathrm{NC}$ lathe, milling machine, machining center and multi axis machine tools, and check the cut, less cut, prevent machine tool collision, over stroke and other errors. Currently has been widely used in aerospace, automotive, mold manufacturing and other industries, and its biggest characteristic is the simulation of CNC system, both the simulation tool file, CAD/CAM and simulation post processing of NC program, the whole simulation process includes program verification, analysis, simulation, optimization, and machine tool model output, etc. System will enter the state of dynamic simulation, and display the effect after the completion of the process, the process as shown in Figure 4.

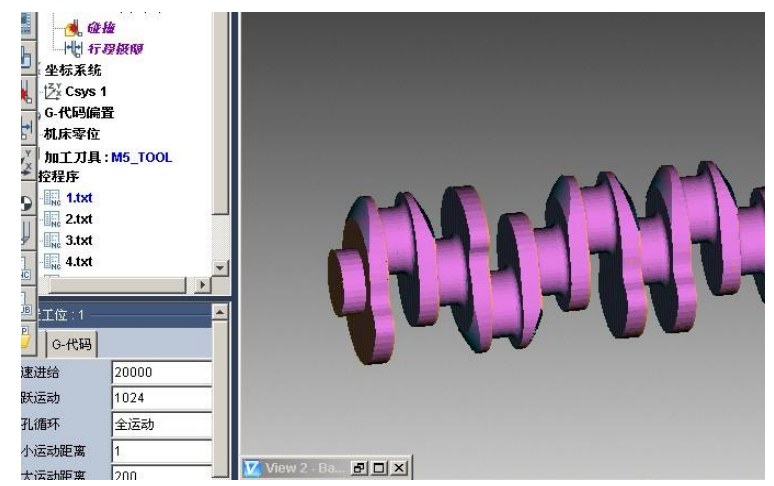

Fig.4 Simulation processing 


\section{Effect Validation}

The crankshaft connecting rod rounded corners through the actual processing, the effect is better, as an example, semi-finishing machining tool rotation speed of 500-600 r/min, feed speed reached 350 $\mathrm{mm} / \mathrm{min}$, roughness between 6.3-12.5 um, Process safety and reliability, the cutting force is small, processing the rounded less than $40 \mathrm{~min}$, efficiency is higher. At the same time, the processing method of cutter is very durable, processing a crankshaft average only need 1-2 pieces of the blade, sharply reduce the tool cost.

\section{Finite Element Analysis of Crankshaft}

The dynamic simulation results show that the maximum load is found in each cylinder, so the static finite element analysis is carried out for the 4 cases when the cylinder is broke out.
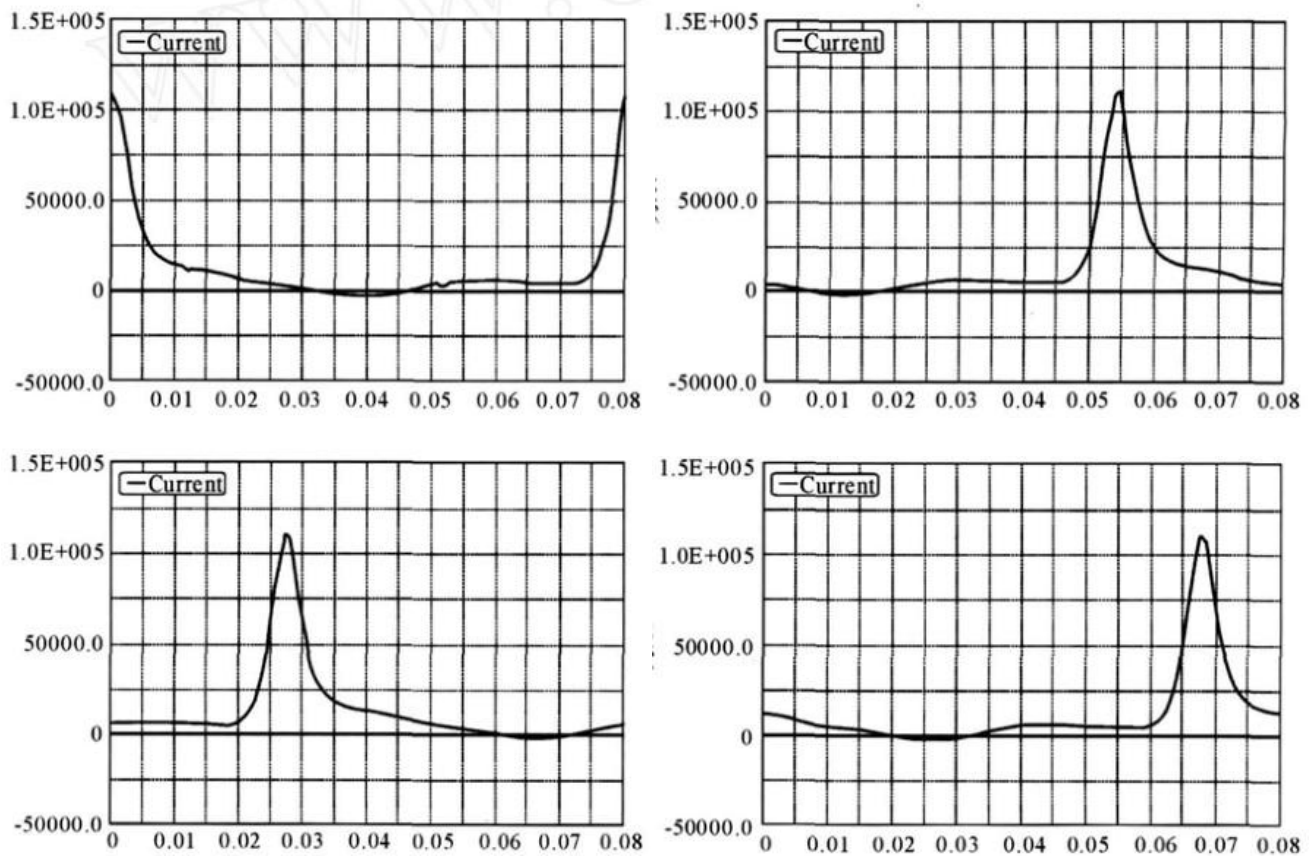

Fig.5. 1 4 Crankshaft connecting rod journal load

The finite element calculation of the crankshaft working process of crank and the main axis of the transition corner near the maximum stress, the Vivtorinox stress peak value of $157 \mathrm{MPa}$, the effective way to reduce stress is to increase the radius of the fillet in a certain range.

\section{Conclusion}

To sum up, Through the finite element analysis of crankshaft to provide a strong basis for the design of the crankshaft, so as to avoid the blindness of design, reduce the design cost and shorten the design cycle,and use the multi-axis linkage processing method, can extend equipment potential, in the turning and milling processing center with a standard spherical cutter processing plan of large crankshaft connecting rod journal fillet, puts forward a new method of connecting rod journal fillet processing, and through the practice shows that effect is good, and the processing effect is high, can reduce the tooling cost, strong practicability, the characteristics of safe and reliable, suitable for promotion.

\section{Reference}

1. Lorenzo Dozio, Massimo Ricciardi. Free vibration analysis of ribbed plates by a combined analytical-numerical method [J]. Journal of Sound and Vibration. 2008 (1). 
2. Zhong Li Juan, Tong Jing Lin. Research and Implementation of Automatic Camshaft Measurement Technology [J]. Key Engineering Materials. 2011 (455).

3. Yi Bao Yuan,,Yu hua Wang.Development of CamshaftJournals Multi-parameters Measuring Inst-rument. Pervasive Computing Signal Processing and Appl-ications (PCSPA),2010 First Inte-rnational Confere-nce on . 2010.

4. I. Lazoglu, C. Manav,Y. Murtezaoglu. Tool path optimization for free form surface machining[J]. CIRP Annals - Manufacturing Technology. 2009 (1).

5. Qiyuan Jin, Xiuzhen Zhang, Turning and milling technology [M], Beijing, Peking University Press, 2010. (in chinese)

6. Yuanqiang Luo, Turning Skills and Taboo[M], Chemical Industry Press, 2009 . (in chinese)

7. Riming zhong, Pro / ENGINEER Wildfire 5.0 from entry to proficiency[M], Beijing, China Machine Press, 2010. (in chinese) 